\title{
TECCIENCLA
}

\section{Gis model of analysis to promote tourism through the use of a web application}

\section{Modelo Gis de análisis para promover el turismo a través del uso de una aplicación web}

\author{
Yuri Vanessa Nieto Acevedo ${ }^{1}$, Oswaldo Alberto Romero Villalobos ${ }^{2}$, Kelly Johanna Gallo Ramírez ${ }^{3}$ \\ ${ }^{1}$ Universidad Distrital Francisco José de Caldas, Bogotá, Colombia, yurivane89@ hotmail.com \\ ${ }^{2}$ Universidad Distrital Francisco José de Caldas, Bogotá, Colombia oromerov@udistrital.edu.co \\ ${ }^{3}$ Universidad Distrital Francisco José de Caldas, Bogotá, Colombia, Kjgallor@udistrital.edu.co
}

\begin{abstract}
The sustainable development of tourism in little-known towns needs the support of web applications and GIS (Geographic Information System) technology. The aim of this paper is to provide a GIS Model of Analysis integrated into a Web Application called Turichia in order to promote tourism in Chía, a small town in Cundinamarca, Colombia, near Bogotá.

The assembly of this web application includes different servers that use ESRI services like Geocoding, Network Analytics, and Web Feature Services and other Geoprocessing operations built in ArcMap for this specific purpose.
\end{abstract}

Keywords: ArcGis Viewer for Flex, Geographic Information System (GIS), Point of Interest (POI), Tourism, Web Feature Service (WFS).

\section{Resumen}

El desarrollo sostenible del turismo en los pueblos no reconocidos necesita el apoyo de las aplicaciones web y la tecnología SIG (Sistema de Información Geográfica). Este artículo describe el análisis de un modelo sig para el desarrollo de una aplicación web denominada Turichia, desarrollada para promover el turismo en Chía, un pequeño pueblo de Cundinamarca, situado cerca de Bogotá-Colombia.

El montaje de esta aplicación web incluye diferentes servicios consumidos desde ESRI como lo son: Servicios de geo codificación, Red Analítica y Web Feature y otras operaciones de geo procesamiento construidas en ArcMap para este propósito específico

Palabras clave: ArcGIS Viwer para Flex, Puntos de interés (POI), Sistemas de información geográfica (GIS), Turismo, Web Feature Services (WFS).

\section{Introduction}

Tourism is considered a potential sector to develop the economy of a region. Little-known towns are lagging behind main towns where people easily find Points of Interest (POI). Tourism in Bogota, as the principal city of Colombia, has rapidly increased in recent years and relies on a number of websites that inform and help people to tour the city. Nevertheless, small bordering towns with interesting places to visit, as is the case with Chia, do not use web applications to help inform tourists about the location, how to get there, and other fundamentals to increase the tourism in the region. As the internet becomes increasingly accessible to large populations [1], tourism in these bordering towns can be positively impacted if cloud-based tourism applications are developed for public use. The Geographic Information System (GIS) is a computer system that allows you to access, save, understand, and display spatial information. GIS technology is already widely used in disciplines such as cartography, geographic, geology survey, environmental 
management, and urban planning, and has become essential in each of these fields [2].

One finds software on the market such as ArcGIS, QuantumGIS, PostGIS, and others that are useful for the objective of tourism promotion through the construction of specific geoprocessing tools and the use of cloud-publishing services [3]. This paper presents a GIS Model of Analysis developed in ArcMap, ArcGIS Server, and ArcGIS Viewer for Flex for display in a web application deployment.

\section{Related work}

Applying the Geographical Information System (GIS) for tourism is nothing out of the ordinary. Years of research and efforts to implement GIS provide a promising approach for successful GIS tourism systems [4]. Shanu [5] proposes an Interactive Multimodal Tourist-Guide System with natural multimodal integration by mouse, keyboard, and speech using .NET, MySQL, JavaScript, and the Google Maps Engine. Tezuka [6] integrates web search with a GIS. Compared to their research, this work extracts information already available on GIS Web Servers and uses it in an integrated web application for people who are interested in tourism in a specific town.

The tourism management method developed by Balqies [7] proposes steps for starting a GIS system for tourism, emphasizing the collection of spatial data. Nisar [8] addresses a related topic, describing in his research the effects of Digital Maps on the tourism industry. However, this research does not solve the problem for small towns where cartography and digital maps are not available with topology or in a tolerable resolution, nor with spatial references for points of interest. This is the reason behind this research project - to show where to find maps already in good shape for tourism applications, when it is convenient to use digital map services or not, and how to reference points of interest using already-existing tools.

Several companies provide geographic information services. Yahoo Local Maps and Google Maps display search results on a map interface [9]. Tomomichi [10] analyzes the quality of data in OpenStreetMap (OSM), which is the geographic information used as the base map for Turichia. The data summarizes the quality needed for geographic information for a specific town [11] [12]:

$\begin{array}{ll}\text { - } & \text { Lineage } \\ \text { - } & \text { Positional accuracy } \\ \text { - } & \text { Attribute accuracy } \\ \text { - } & \text { Logical consistency } \\ \text { - } & \text { Completeness } \\ \text { - } & \text { Semantic accuracy } \\ & \text { Usage, purpose and constraints } \\ & \text { Temporal quality }\end{array}$

\section{Methods}

To ensure high efficiency, flexibility, scalability for the WebGIS system, the system uses enterprise architecture, related to what Yang [13] proposes in his research to represent his system architecture. The system is divided into a Database layer, GeoServices layer and Client layer, as shown in Figure 1.

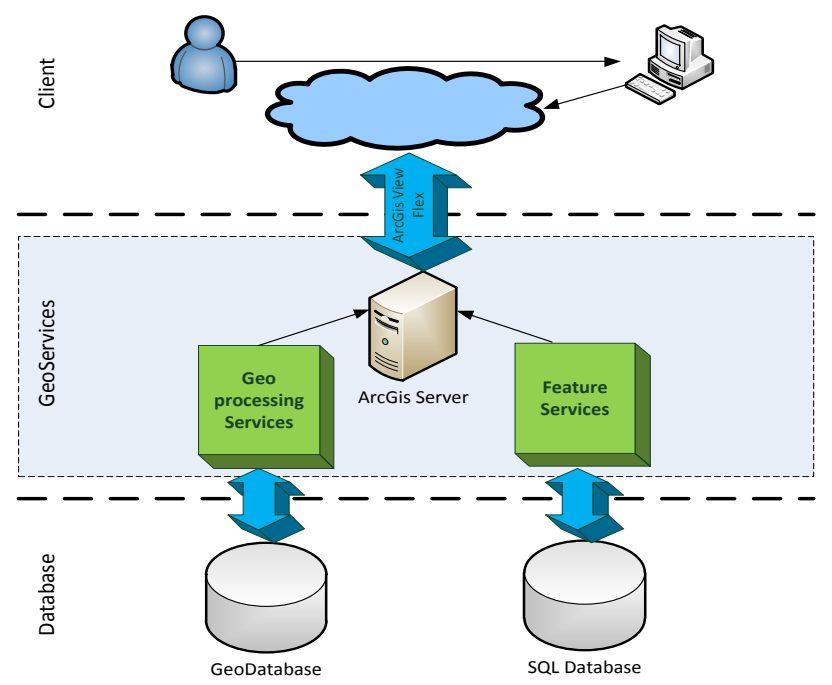

Figure 1. Turichia System Architecture

\subsection{Database Layer}

Once the objectives of the Tourism Web Application are defined, the work starts by collecting all types of data in different forms and shapes to build a GIS, followed by the procedures explained below. The collected data needs to be divided into two main types: Spatial data and Attribute data [7].

\subsubsection{Defining spatial data}

Spatial data is related to space and its position on the surface of the earth [14]. The Mayor's Office of the town of Chia has provided the street level data of the town in AutoCAD, but this represents a big challenge to the project due to the fact the data has to be converted into a shape file with topology [15] to be subsequently used in ArcGIS 10.2, which is the main software used to develop this project. Nonetheless, OpenStreetMap (OSM) already offers a goodquality street map for the town replete with topology that is available for use in ArcGIS and is thus the base map for this project, similar to the alternative solution proposed by Marek [16] in his route planning model using OSM.

\subsubsection{Defining attribute data}

This information is limited in Chia, since it is a small town 


\section{TECCIENCIA}

that has not explored tourism - indeed, they have not had data on points of interest collected. This data is gathered by the Mayor's Office in table form with names and addresses. Points of Interest (POI) situated in mountains or villages are located using OSM by residents of Chia who have lived in the town and known it for a long time. These POIs are categorized into nine groups: administrative, gastronomic, cultural, recreational, religious, safety, health, malls, and bars.

\subsubsection{Data processing:}

In order to georeference the Points of Interest, Google Maps is used to locate the latitude and longitude of each POI, employing the WGS84 geographical coordinate system [17]. Because POIs are a kind of data point which are not affected by distortion, as can occur with polygon data, it is not necessary to establish a projection system. All of this takes as reference the work developed by Ardizzone [18] and List [19] to extract tourism information using Google Maps.

\subsubsection{Building a geodatabase:}

Here, information about features is provided in tabular form to allow analysis with clear presentation and real interaction with the needed information [20]. This form contains attribute data such as the identification number, name, latitude, longitude, description, address, telephone number, and website. It is an Excel spreadsheet that is exported using the ArcMap function AddXY to convert it into a shapefile. ArcCatalog is employed to set up the new geodatabase: the POI data set and the feature classes, or the nine categories established above. Then, an enterprise geodatabase is created using ArcToolBox. Roi [20], in his research on constructing databases in ArcGis, describes a methodology to attain this same objective using ArcSDE services [21]. In the case of the Web Feature Service, it is recommended to use a relational database that supports spatial data types such as PostGis, MySQL, Oracle, SQL, etc. [22]. Using the query language offered by $\mathrm{SQL}$, a requirement statement is created to georeference each POI, creating a new field on the table as a type of geographical data, as follows:

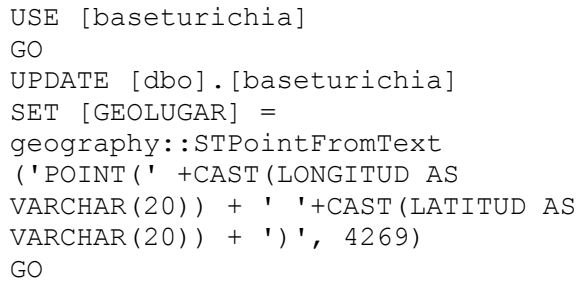

This expression takes the data in the fields of latitude and longitude and makes them spatial data in the new field Geopoint, taking the SRDE code 4269, which is an ArcGIS Dynamic Map Service Layer with a Spatial Reference WKID [23]. It is also important to create a default instance with a password while SQL is being installed in order to avoid issues with the connection to the database.

\subsection{Generating Services}

As a result of the analysis of the requirements made through UML [24] in the construction of the Use Case diagram and the Class diagram for an application that is expected to promote tourism using GIS technology, two kinds of services are generated, such as geoprocessing operations built in ArcMap and servers accessed from ArcGIS Online.

The client for this kind of web application needs answers to questions such as, "What Points of Interest are there in this town?," "Where are they located?," "How can I get there?," [25] "What is the nearest POI to me?," "Which POIs are located near my radius area?," "Where is this address?," and "Can I contribute to this web application by adding/editing POIs?". In order to answer these questions, the following services are built:

\subsubsection{Geoprocessing services using ArcMap}

Using the ArcToolBox, geoprocessing models are created using tools such as select, near, join field, buffer, and clip:

- Query and Search: Using ArcMap, the alreadycreated GeoDatabase is uploaded. It is necessary to fill the Map properties file and to save the .mxd file to subsequently publish the service. The URL that results from this procedure is later used in ArcGis Viewer for Flex. This is similar to the methodology used by Quian-quian [26] in his research.

- Nearest distance: Using the select tool, the client can choose the place where he is located, followed by the near tool to determine the nearest POI. Finally, with the join field tool, the client can visualize the attributes of this POI. Figure 2 shows this model. 


\section{TECCIENCIA}

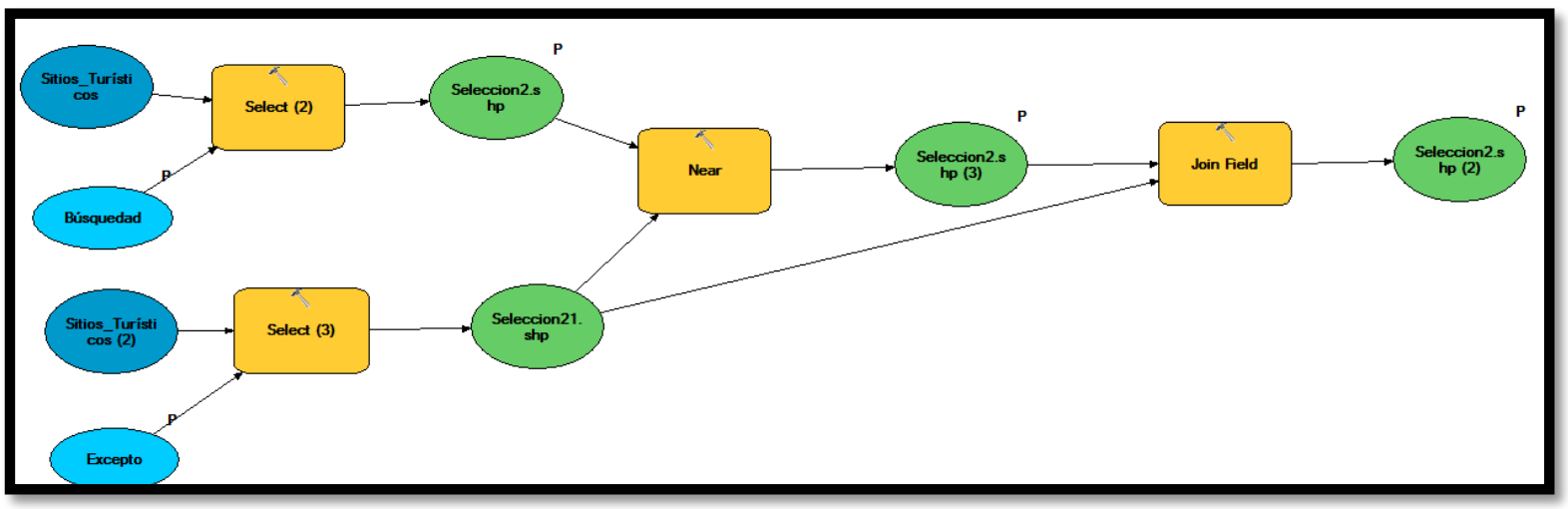

Figure 2. Model in ArcMap to find the Nearest distance to a POI

- $\quad$ POI within a radius ring: This model is similar to the nearest distance model explained above. Nevertheless, this model includes the buffer tool to determine the radius in meters to the client's location where POIs can be found. The model is shown in Figure 3.

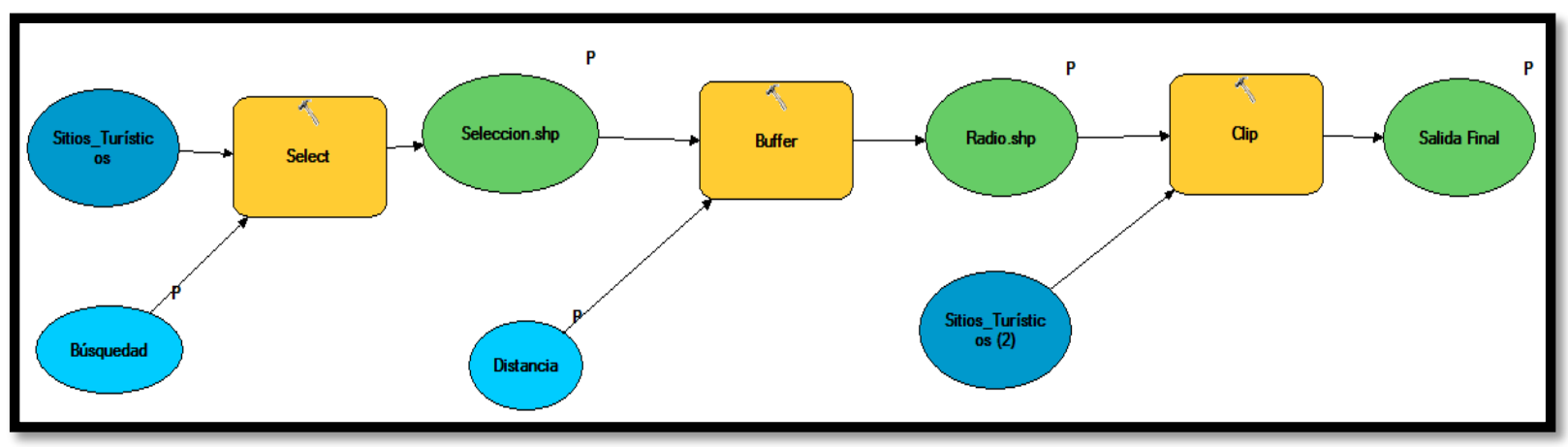

Figure 3. Model in ArcMap that finds Points of Interest within a radius ring.

It is vital to configure the input and output data as parameters in order to enable clients to pick existing data.

\subsubsection{Servers accessed from ArcGIS online}

Once all servers are integrated into ArcGIS Viewer for Flex, it is possible to access the servers offered by ArcGIS Online. In this section, only the servers and their functionality are explained. However, web application integration will be discussed in the next section with the results from ArcGIS Viewer for Flex.

- Network Analysis: This method is based on graph theory and operational research and is used as a method for geographic modeling and urban infrastructure networks. It is applied for the optimum allocation of resources, the search for the shortest path, and so on [27]

- Using the Network Analysis module from ArcGIS Online, as Yang [28] proposes, it is possible to answer the question, "How can I get there?" Besides, there are other complementary options, such as add a barrier, calculate time and distance, and show the step by step sequence.
- Geocoding: This method find associated geographic coordinates from other geographic data such as street addresses or ZIP codes [29]. In Turichia, the service accessed from ArcGIS Online permits the location of an address using a single input field, in this case the address. The output point can be visualized on the map. Once the address is entered, a dashboard with the possible location options is shown, with the aim being that the client can choose the more accurate option.

- Web Feature Service (WFS): This is an ArcGIS Online service that enables a client to retrieve geospatial data encoded in Geography Markup Language (GML) online through HTTP protocol. It allows clients and servers of different vendors or systems to share data without having to convert data between proprietary formats. The WFS server is thus a featured online resource, providing an interface for data access and manipulation. WFS enables crowdsourcing, due to the fact end users can add and edit existing POIs. A request sent to the WFS server is a query (or transformation operation) for one or more features that can be delivered by a server. When WFS receives the request, it executes the function for the 


\section{TECCIENCIA}

request and sends the information back to a client. WFSs communicate with a client and allow programs written in different languages and on different platforms [22]. The workflow of the WFS process service is shown in Figure 4.

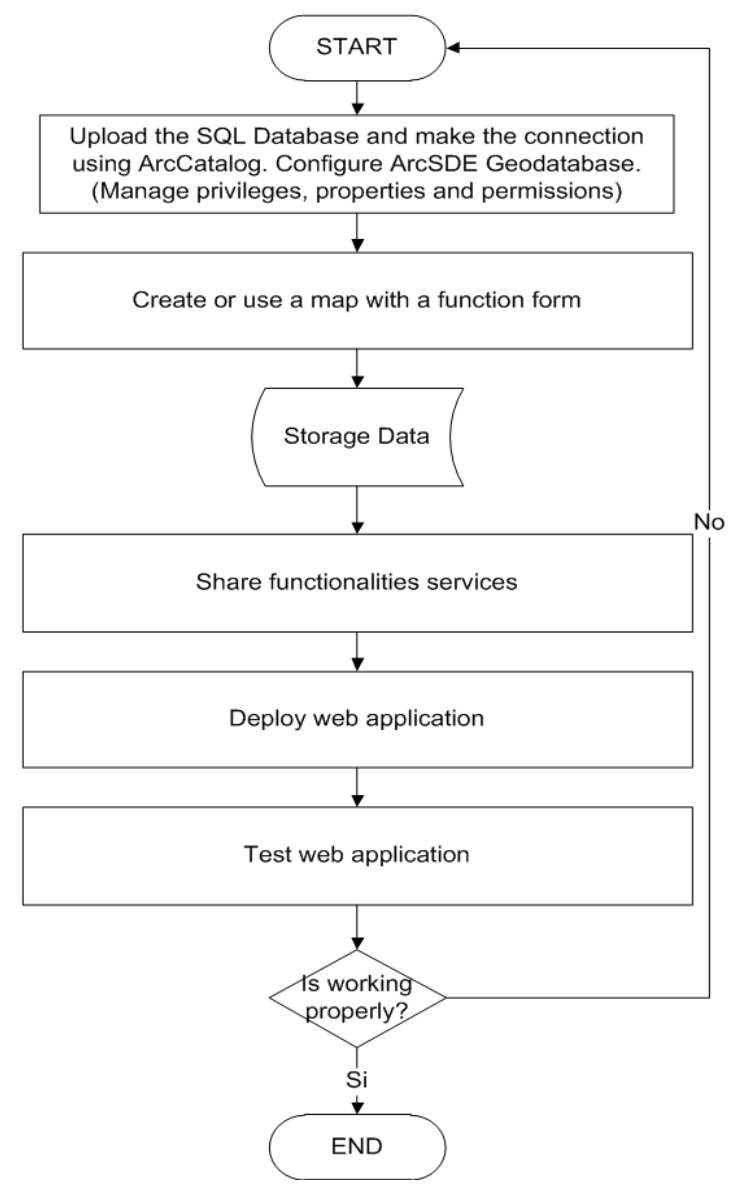

Figure 4. Workflow for WFS development.

The key design feature of the WFS service system is to satisfy the user request for different versions of WFS services [30]. In order to enable the multi-version WFS service, a spatial database is created in SQL to ensure clients can access reliable data without affecting the geodatabase previously created in ArcCatalog. This means Turichia has two databases to protect data. Clients add and edit attribute data directly from the SQL database. For future work, we propose the creation of a database administrator role to approve WFS operations and upload and make changes to the geodatabase.

\subsection{Integrating the Web Application using ArcGIS Viewer for Flex}

Flex Viewer is the use of ArcGIS API for Flex and Flex Framework for design and implementation, which can be removed for the display of (out-of-the-box) rich Internet applications, supported by ArcGIS Online, ArcGIS Server

and other access services (GeoRSS, etc.). Flex has extensive libraries for developers that enable developers to build an efficient, powerful, and aesthetically beautiful internet application more easily [31]. It is necessary to configure five tabs or modules, such us:

- Extension: In this tab it is imperative either to add a base map or choose one map from the ones available. Due to the fact that the digital map of Chia was not of good resolution, as was previously mentioned, Open Street Map is used as the base map. Additionally, the SQL spatial database is arranged as the operational layer, already connected as an enterprise geodatabase.

- Widgets:The widget module is designed to reduce heavy complex programming work such as map management, map navigation, application configuration, and communication between components. Developers can thus focus on the development of core business function. Only in the Flex Viewer configuration file for adding configuration items can this work in the form of rapid display control from within the existing Flex Viewer application [13]. Through the URL resulting from the published services on ArcMap, the developer makes a call to the services and uses the already existing ones on Flex. The widgets that Turichia uses are represented in Table 1.

- Table 1. Turichia widgets

\begin{tabular}{|c|c|c|}
\hline Widget & Functionality & $\begin{array}{c}\text { Kind of } \\
\text { GIS service }\end{array}$ \\
\hline Q. Q.m & $\begin{array}{l}\text { Query: Enables end users to query } \\
\text { information from a map service by } \\
\text { executing a predefined query. }\end{array}$ & $\begin{array}{l}\text { ArcMap- } \\
\text { created } \\
\text { Model. }\end{array}$ \\
\hline searon & $\begin{array}{l}\text { Search: Enables end users to search for } \\
\text { features in a specific layer using a } \\
\text { geographical search tool. }\end{array}$ & $\begin{array}{l}\text { ArcGIS } \\
\text { Online } \\
\text { service }\end{array}$ \\
\hline tosene & $\begin{array}{l}\text { Geocoding/Locator: Enables end users } \\
\text { to find a location on the displayed map } \\
\text { content in the Viewer. }\end{array}$ & $\begin{array}{l}\text { ArcGIS } \\
\text { Online } \\
\text { service }\end{array}$ \\
\hline $\begin{array}{c}6 \\
66 \\
\text { Route Widget }\end{array}$ & $\begin{array}{l}\text { Network Analysis: Enables end users to } \\
\text { find the shortest path from a place. }\end{array}$ & $\begin{array}{l}\text { ArcGIS } \\
\text { Online } \\
\text { service }\end{array}$ \\
\hline 100 & $\begin{array}{l}\text { Nearest Distance: Enables end users to } \\
\text { find the nearest POI. }\end{array}$ & $\begin{array}{l}\text { ArcMap- } \\
\text { created } \\
\text { Model. }\end{array}$ \\
\hline 100 & $\begin{array}{l}\text { POI within a radius ring/Buffer: } \\
\text { Enables end users to find the Points of } \\
\text { Interest contained within a selected } \\
\text { radius. }\end{array}$ & $\begin{array}{l}\text { ArcMap } \\
\text { created } \\
\text { Model. }\end{array}$ \\
\hline 7 & $\begin{array}{l}\text { Web Feature Service: Provides end } \\
\text { users with a clear and intuitive editing } \\
\text { experience. }\end{array}$ & $\begin{array}{l}\text { ArcGIS } \\
\text { Online } \\
\text { service }\end{array}$ \\
\hline 6 & $\begin{array}{l}\text { Print: Enables end users to print what- } \\
\text { you-see is-what-you-get (WYSIWYG) } \\
\text { output, meaning all visible map display } \\
\text { is printed. }\end{array}$ & $\begin{array}{l}\text { ArcGIS } \\
\text { Online } \\
\text { service }\end{array}$ \\
\hline
\end{tabular}




\section{TECCIENCIA}

- Composition: This module allows the developer to edit and activate the dashboard function for the application such as the scale bar, coordinates, navigation, URL, general view map, search panel, etc.

- Design: The design tab enables the developer to edit titles, letter style, color scheme, and transparency, and allows the uploading of an image for the application logotype.

- Preview: This module is an interactive preview of the application and where all previously-setup functions can be executed. This tab also generates a URL application for subsequent use [32]. Initially, Turichia has the IPs http://10.20.161.100/turichia http://turichia.udistrital.edu.co for academic example. The infrastructure will subsequently be installed at the Universidad Distrital server and configured with a publicly assigned IP; in the meantime, this IP address and Web Address is an example for reference.

\section{Results}

Based on the system architecture above, this model has deployed a version of the Flex Viewer application as a practical system. The application is shown in Figure 5.

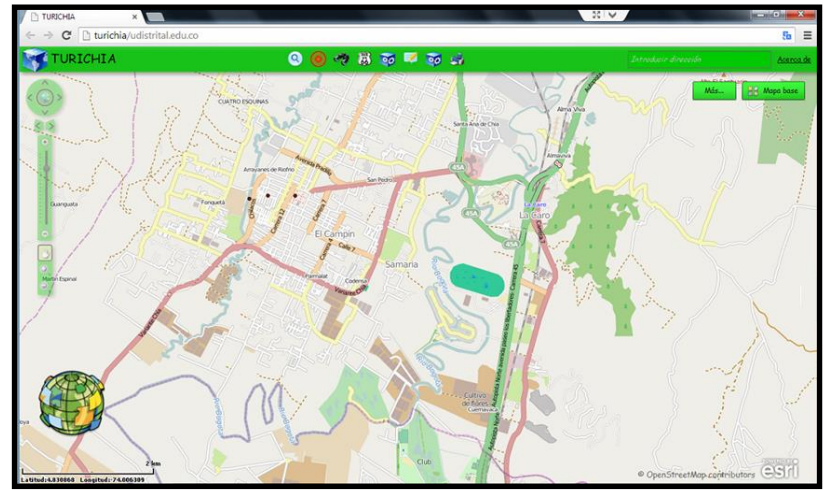

Figure 5. Application interface of Turichia

The services provided by the application can be seen as follows:

When the query application is executed, a dashboard popsup on the left to show all the Points of Interest registered on the geodatabase, as shown in figure 6. Initially, the application has forty-five entities. Once the end user clicks on the query widget, a new dashboard displays information about the selected POI.

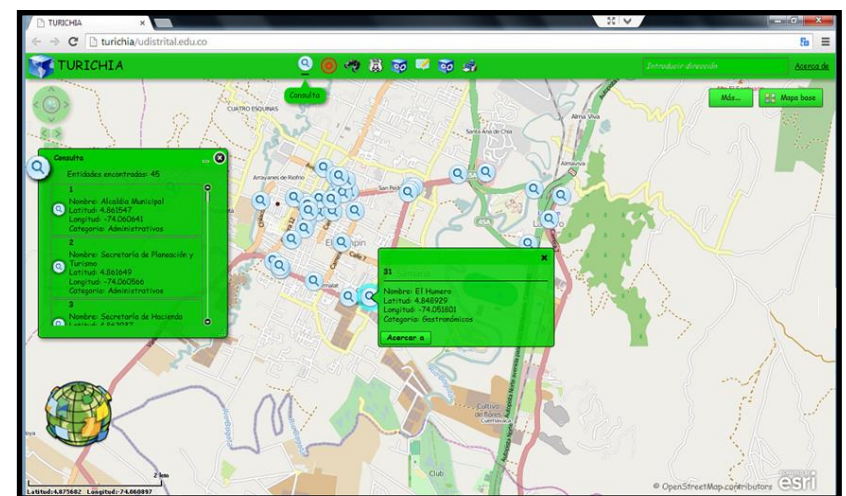

Figure 6. Query Geoprocessing result

The Locator application allows the end user to insert the address he is looking for into a textbox. This uses geocoding services to locate addresses on the map. It also finds related addresses in order to allow the client to choose the most accurate search result. The dashboard also displays scores based on geocoding proximity which are not lower than 97 points out 100 for Turichia, as shown in figure 7. It is necessary to configure the Chia area into the preliminary options of Viewer for Flex so that the application does not pull up addresses from out of the area of the town.

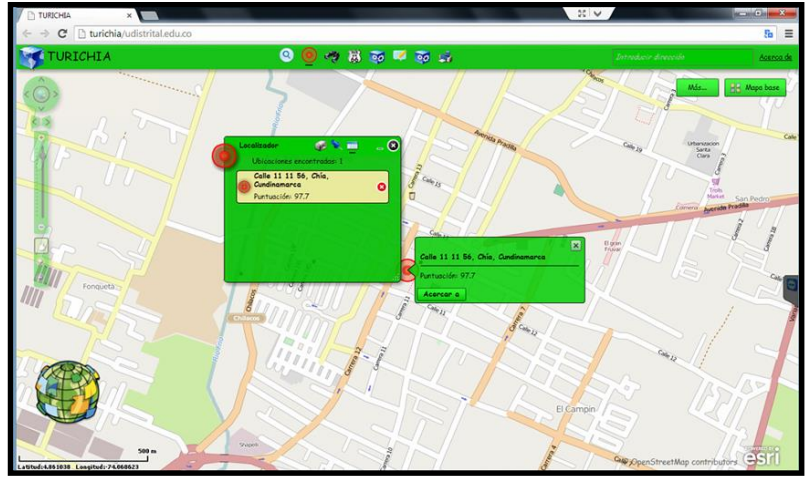

Figure 7. Geocoding services result

One of the services that we are creating, modeling, and publishing for Turichia is locating POIs within a radius ring. When the widget is activated, a new dashboard allows the end users to indicate the radius area in meters. A scaled grey shadow appears on the map, indicating the radius and the POI content inside this buffer. The information about each POI is shown when the user clicks on it. The results of the application on Turichia are shown in figure 8 . 


\section{TECCIENCIA}

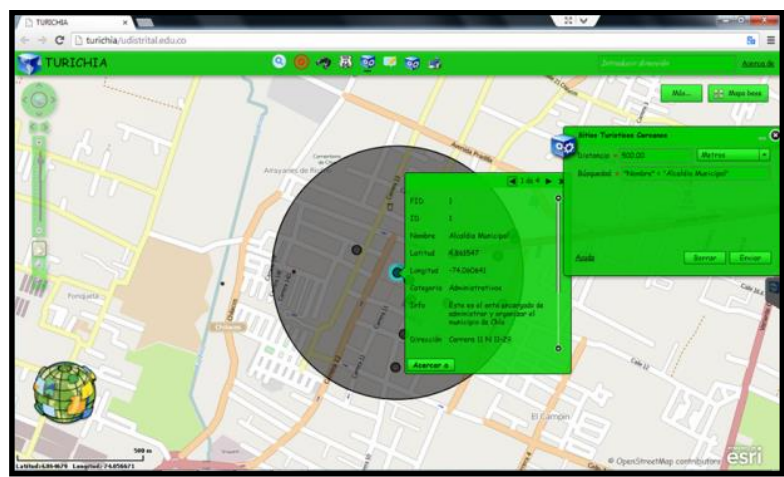

Figure 8. Buffer Geoprocessing results.

The Web Feature Service is the only service that works in Turichia with the SQL database, as explained above. This service allows the end user to add and edit POIs included in the SQL database. Nevertheless, these new POIs are not available to be searched or used by other services. This is because the connection between the Geodatabase and the SQL database has not been established. It is recommended for future work to create an administrator role with the aim of approving WFS operations and uploading and making changes on the Geo Database. With these services, other options can be explored, such as uploading photographs or videos of visited places. The WFS service in Turichia is shown in figure 9.

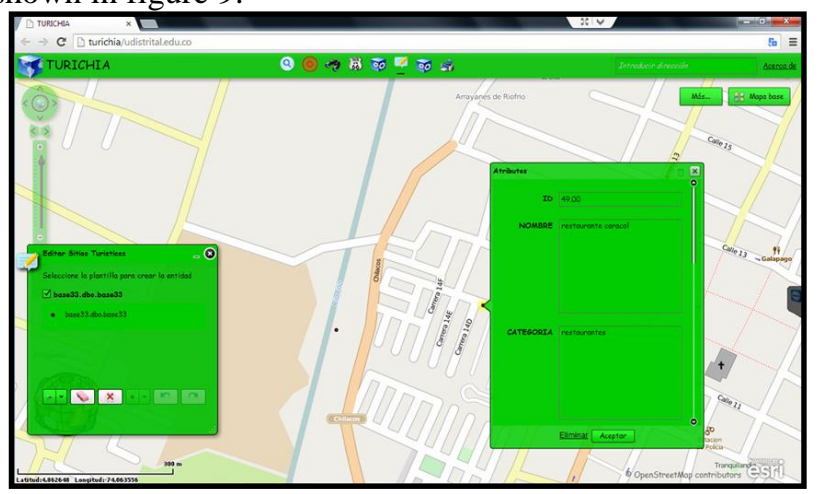

Figure 9. Web Feature Services results.

\section{Conclusions}

A model of analysis has been proposed using ArcGIS as the main software to develop and deploy a web application to promote tourism. Building a GIS system for tourism is a great start in planning for better services in any city. This model of analysis was tested in Turichia and works as a methodology for creating new tourism applications, including mobile applications, desktop applications, web browser applications, etc., for other towns with a simple change of the base map and the operational databases - in other words, by changing the city information, the same model could be applied.

To conclude, we expect it to soon include the role of approving operations organized in WFS, creating route- planning suggestions, inserting photographs of POIs, and so on.

Developing web GISs based on Flex Viewer is a current trend, due to the fact that it is an easy non-programming method of creating applications where models constructed in ArcMap and services that are already on the cloud can be integrated. As a friendly and helpful application for tourists, it provides social benefits for the town. Moreover, it provides a good mechanism for documenting, conserving, and monitoring Points of Interest in a town.

\section{References}

[1] G. Chang y L. Caneday, «Web-based GIS in tourism information search : Perceptions , tasks , and trip attributes,» Tourism Management, vol. 32, $\mathrm{n}^{\circ}$ 6, pp. 1435-1437, 2011.

[2] F. Liu, J. Zhang, J. Zhang y Y. Zhu, «Geostatistical analysis of China inbound tourism spatial distribution structure,» de Geoinformatics, 2010 18th International Conference, Beijing, 2010.

[3] Z. Peng, L. Mei, W. Fei y Y. Fei, «The analisis of Gis software engineering pattern under the cloud computing environment,» de Educational and Information Technology (ICEIT), 2010 International Conference, Chongquing, 2010.

[4] A. Emhmed y K. Chellapan, «GIS-based mobile tourism architecture prototype for Libya (A case study),» de Information Technology (ITSim), 2010 International Symposium, Kuala Lumpur, 2010.

[5] S. Sharma y A. Agrawal, «IMTS- an Interactive Multimodal Tourist-Guide System,» de Signal and Image Processing (ICSIP), 2010 International Conference, Chennai, 2010.

[6] T. Tezuka, T. Kurashima y K. Tanaka, «Toward tighter integration of web search with a geographic information system,» de Proceedings of the 15th international conference on World Wide Web, New York, 2006.

[7] B. Sadoun y O. Al-Bayari, «A GIS system for tourism management,» de Computer Systems and Applications, 2009. AICCSA 2009. IEEE/ACS International Conference, Rabat, 2009.

[8] K. Nisar y H. Hasbullah, «The effect of panoramic view of a digital map on user satisfaction - a tourism industry's case study,» de Information Technology, 2008. ITSim 2008. International Symposium, 2008.

[9] Y. Kawai, J. Zhang y H. Kawasaki, «Tour recommendation system based on web information and GIS,» de Multimedia and Expo, 2009. ICME 2009. IEEE International Conference, New York, 2009.

[10] T. Hayakawa, Y. Imi y T. Ito, «Analysis of Quality of Data in OpenStreetMap,» de Commerce and Enterprise Computing (CEC), 2012 IEEE 14th International Conference, Hangzhou, 2012.

[11] M. Haklay, «How good is volunteered geographical information? A comparative study of OpenStreetMap and Ordnance Survey datasets,» Environment and planning B: Planning and design, vol. 37, pp. 682-703, 2010.

[12] P. Van Oort, «Spatial data quality: from description to application,» de Publication on Geodesy 60. Geodetic Commission, Netherlands, 2006.

[13] Y. Yang, L. Shao, Y. Zhu y K. Yang, «A study on Erhai Lake environment information service base on ArcGIS and Flex,» de Geoinformatics, 2011 19th International Conference, Shanghai, 2011.

[14] S. Wang, «Spatial data mining under Smart Earth,» de Granular Computing (GrC), 2011 IEEE International Conference, Kaohsiung, 2011. 


\section{TECCIENCIA}

[15] Y. Duan, C. Wang y W. Zhou, «Topology modeling of distribution network based on open-source GIS,» de Electric Utility Deregulation and Restructuring and Power Technologies (DRPT), 2011 4th International Conference, Weihai, Shandong, 2011.

[16] M. Malowidzki, M. Mazur, T. Dalecki y P. Berezinski, «Route planning with dynamic data,» de Military Communications and Information Systems Conference (MCC)., St-Malo, 2013.

[17] F. Fell y M. Tanenbaum, «Preliminary comparisons of the WGS84(EGM 96) geoid with national vertical datums,» de OCEANS, 2001. MTS/IEEE Conference and Exhibition, Honolulu, 2001.

[18] E. Ardizzone, F. Di Miceli, M. La cascia y G. Mazzola, «Extracting Touristic Information from Online Image Collections,» de Signal Image Technology and Internet Based Systems (SITIS), 2012 Eighth International Conference, Naples, 2012.

[19] A. Popescu, P. Moëllic y I. Kanellos, «Themeexplorer: Finding and browsing geo- referenced Images,» de Proceedings of the International Workshop, London, 2008.

[20] D. Rong, X. Dayuan, G. Luo y S. Faming, «Research on Constructing a Traditional Knowledge Database Information System Based on ArcGIS Server,» de Intelligent Networks and Intelligent Systems (ICINIS), 2012 Fifth International Conference, Tianjin, 2012.

[21] H. Lin y B. Huang, «SQL/SDA: a query language for supporting spatial data analysis and its Web-based implementation,» Knowledge and Data Engineering, IEEE Transactions, vol. 13, $\mathrm{n}^{\circ}$ 4, pp. 671-682, 2001.

[22] S. Chunithipaisan y S. Supavetch, «The Development of Web Processing Service Using the Power of Spatial Database,» de Emerging Trends in Engineering and Technology (ICETET), 2009 2nd International Conference, Nagpur, 2009.
[23] S. Zhou, J. Liu, B. Wan y L. Yang, «Seamless integration of SQL Server spatial data on GIS platform,» de Geoinformatics, 2010 18th International Conference , Beijing, 2010.

[24] A. Tucker, Computer Science Handbook, Second Edition., CRC Press, 2004.

[25] C. Ryan, Researching tourist satisfaction : issues, concepts, problems, London: Rountledge, 1995.

[26] Qian-quian y Xu, «A kind of geographic information system application based on flex API of ArcGIS Server,» de Advanced Computer Theory and Engineering (ICACTE), 2010 3rd International Conference on, Chengdu, 2010.

[27] T. Guo An, Experimental Course for Spatial Analysis of ArcGIS, Science Press, 2012.

[28] Z. Yang, S. Lu y X. Jin, «Tourism spatial association analysis based on GIS technology for the cities in Anhui of China,» de Geoinformatics, 2011 19th International Conference, Shanghai, 2011.

[29] E. Ardizzone, F. Di Miceli, M. La Cascia y G. Mazzola, «Extracting Touristic Information from Online Image Collections,» de Signal Image Technology and Internet Based Systems (SITIS), 2012 Eighth International Conference, Naples, 2012.

[30] J. He, N. Chen y W. C. Z. Wang, «A dynamic schema matching approach for multi-version web feature service retrieve,» de Geoinformatics, 2009 17th International Conference , Fairfax, 2009.

[31] Z. Wei, J.-H. Kim y J. Zhao, «Research of Flex-based WebGIS application.,» de International Conference on Networked Computing and Advanced Information Management, Seoul, 2010.

[32] M. Peterson, Online Maps with APIs and WebServices, Berlin: Springer, 2012. 